\title{
Gendered Authorship and Demographic Research: An Analysis of 50 Years of Demography
}

\author{
Sandra Krapf ${ }^{1} \cdot$ Michaela Kreyenfeld $^{2,3}$. \\ Katharina Wolf ${ }^{2,4}$
}

Published online: 11 July 2016

(C) The Author(s) 2016. This article is published with open access at Springerlink.com

\begin{abstract}
Demography, the official journal of the Population Association of America, has been given the highest rating among demographic journals by the Social Sciences Citation Index (SSCI). Our aim here is to investigate the development of research subfields and female authorship in Demography over the last 50 years. We find that female authorship in Demography has risen considerably since the 1980s and that currently a woman is about as likely as a man to be the sole or the first author of a paper published in the journal. However, we find some differences by subfield. Women seem to be overrepresented in the "family and household" research subfield but underrepresented in the "mortality and health" and "data and methods" categories.
\end{abstract}

Keywords Demography $\cdot$ Publication practices $\cdot$ Female authorship $\cdot$ Gender · Bibliometrics

\section{Introduction}

Considerable evidence suggests that women are now outperforming men in formal education in most industrialized countries (OECD 2012). In the United States, more women than men are earning Master's and $\mathrm{PhD}$ degrees (Gonzales et al. 2013). Tower et al. (2007), who examined the publication output of women and men in top journals

Michaela Kreyenfeld

kreyenfeld@hertie-school.org

1 University of Cologne, Cologne, Germany

2 Max Planck Institute for Demographic Research, Rostock, Germany

3 Hertie School of Governance, Berlin, Germany

4 Population Research Centre, Faculty of Spatial Sciences, University of Groningen, Groningen, The Netherlands 
listed in the Thompson ISI index, even concluded that male and female researchers have reached parity in publication output, when the percentage of women in the respective academic field is controlled for. However, more recent studies on women's academic performance have challenged the idea that the gender gap in publication output has narrowed (Abramo et al. 2009; West et al. 2013). These critical voices have called for a more nuanced exploration of gender and scientific authorship. West et al. (2013) reported that men often hold the prestigious position of first author and that even in more gender-equal fields, gendered authorship is still prevalent in certain subfields. Because the number and the quality of scientific publications are key elements of career advancement in science (Ramsden 1994), it is important that we understand the gendered patterns in research productivity.

At first glance, the gender balance in demographic research seems to be better than it is in other fields of research: $41.9 \%$ of all authors of demographic studies published from 1990 to 2011 are women (West et al. 2013:2). ${ }^{1}$ However, we have no information on the question of whether the increase in female authorship was accompanied by an equal increase in the share of female first or sole authors in demographic research. We also do not know whether there is gender segregation by demographic subfields. We seek to contribute to this research by exploring the development over time of gender gaps in scholarly authorship within subfields of demography. Specifically, we focus on all issues of Demography, the flagship journal of the Population Association of America (PAA), which was launched in 1964 and recently celebrated its 50th anniversary. Although previous studies have examined the patterns of publication activities in Demography (Teachman et al. 1993; Watkins 1993), no study has explored recent trends. Here, we examine the question of whether there is a gendered pattern of publication by demographic subfield, such as mortality, fertility, or family and household research. We also investigate whether men and women are equally likely to hold the prestigious position of first author for papers with multiple authors. Our empirical analyses are based on the bibliometric information on each article published in Demography for the period 1964 to 2014. However, we note two main caveats of our analysis. First, the analysis of articles of a single journal does not allow us to draw conclusions for the entire field of demography. An analysis of all demographic journals, and particularly of those published in other countries, may lead to different outcomes. Second, we assigned articles manually to different subcategories. We believe that our procedure is superior to a computerized classification procedure for reasons discussed in more detail later in the article. However, in several cases, we could not assign a paper unambiguously to a single research subfield.

\section{Background}

The female-male ratio in publications has frequently been used as a bellwether for gender equality and women's advancement in science. Although the research results are somewhat mixed, the share of authors who are women appears to have increased considerably in recent decades in several fields and across countries (Østby et al. (2013) for the field of international relations; Mauleon et al. (2013) for Spain; Woerdeman and Rodgers (2006) for the Netherlands and the United Kingdom).

\footnotetext{
${ }^{1}$ The authors used all of the publications archived in JSTOR.
} 
However, some studies (Abramo et al. 2009; Leahey 2006; West et al. 2013) have challenged the view that the gender gap in scientific publication has disappeared. These authors have argued that most of the studies that found no disparities examined large research fields while systematically overlooking gender imbalances in more narrowly defined subfields. For example, in sociological publications, female authors are overrepresented in subfields such as gender and early childhood but are underrepresented in other subfields (West et al. 2013:3). In an investigation of gender differences in subfields of economics research, Dolado et al. (2012) found that although $37 \%$ of the researchers who earned a $\mathrm{PhD}$ between 1996 and 2005 in the top 50 departments in the fields of health, education, and welfare are women, less than $20 \%$ of faculty in the subfield of mathematical and quantitative methods are women. Authorship practices also appear to differ by gender. West et al. (2013) reported, for example, that men predominate in lead authorship.

Several mechanisms that might result in a gender imbalance in research subfields have been identified (for a discussion, see Dolado et al. 2012). The arguments regarding these mechanisms are very much in line with those made in research on occupational sex segregation (Blau et al. 2013; Reskin 1993; Trappe and Rosenfeld 2004). For our research question, two arguments seem to be of specific relevance. First, women may self-select into particular areas of research — such as subfields of early education, family, and household - based on "taste" (Dolado et al. 2012). Second, "network effects" may pull women into research fields in which members of their own gender are already heavily represented (Reskin 1993). Thus, women tend to be hired and promoted in fields in which gender segregation is already pronounced (Cohen et al. 1998).

In this study, we are unable to tease out selection and network effects. Our goal is more modest: namely, to give a descriptive account of the prevalence of female authorship in Demography. We also explore the question of whether women's chances of being the lead or the sole author of a publication have been rising in tandem with the general increase in women's publication activities.

\section{Data}

To study the gender patterns of publication in research subfields in the journal Demography, we had to identify the gender of all of the authors and the research subfield in which each article was published (for a detailed description of the data collection and categorization procedure, see Nieberg et al. 2014). The citation information for all of the publications in Demography was drawn from the online JSTOR database and the Web of Science database, which covers the Science Citation Index Expanded, the Social Sciences Citation Index, and the Arts and Humanities Citation Index.

The key independent variable in our investigation is the gender of the author. However, the citation information obtained from Web of Science and JSTOR does not note the author's gender. Using the first names provided in the literature databases, we used the program "gender.c" to identify the authors' gender. ${ }^{2}$ This program contains a list of first names for all European countries, for the United States, and for some Asian

\footnotetext{
${ }^{2}$ The copyright (2007-2008) for this program lies with Jörg Michael, Adalbert-Stifter-Str. 11, 30655 Hannover, Germany. The program is subject to the GNU Lesser General Public License (LGPL), as published by the Free Software Foundation.
} 
countries (e.g., China, India, and Japan). According to the program's developer, the decision rules for assigning the typical gender to each name are based on assessments provided in interviews with several native speakers and experts. The program assigns a gender to each first name if it is typically given to either males or females, and it flags unisex names. If a name was coded as unisex or as not classifiable, we identified the gender of the author manually through online research. We were unable to retrieve the gender of the author in 185 cases ( $4 \%$ of the full sample). These cases were omitted from our analysis. The total sample contains 2,252 articles with 4,197 authors.

Categorizing articles by research area was the most challenging task in our analysis. After experimenting with several options, we decided to assign each article to a single category only (for a similar strategy, see Abramo et al. 2009; Dehdarirad et al. 2015; Dolado et al. 2012; Maliniak et al. 2013; West et al. 2013). Furthermore, we based the categorization of the papers on the dependent variable (see also Teachman, et al. 1993). Because demography is an applied field of research, the classification of the papers by the dependent variable seemed straightforward and easily reproducible. However, ambiguous cases remained, especially if a paper was more theoretical or covered a broad range of topics. An alternative approach might have been to use a more objective, computer-assisted classification procedure that used keywords searches. However, using a computer-based approach has disadvantages, particularly if it is based solely on a frequency count of words. For example, even if a word search showed that the term "fertility" appeared more frequently than the term "migration" in a paper, it would still be difficult to judge whether the paper was on migration or on fertility. We thus determined that a more qualitative approach that could take into consideration the chief objective of a paper (by focusing on the dependent variable) was the better option.

Before we could assign articles to subcategories, we had to create these categories. In this case as well, computer-based approaches might have been applied to generate subfields (see, e.g., Merchant 2015). We rejected this option because the core subfields in demography are well defined. Demographers generally agree that the main pillars of demographic research are fertility, mortality, migration, and methods. We therefore used these four narrow subfields as the basis for our classification procedure. After analyzing a sample of articles published in Demography, we extended this classification to include the following categories:

- Fertility

- Family and household

- Mortality and health ${ }^{3}$

- Migration

- Data and methods

- Other

To help us assign each article to one category only, we developed a list of keywords for each subfield (see Table 2 in the appendix). In a pre-test we grouped the different articles based on the list of keywords alone. However, we later determined that the inclusion of additional decision criteria would improve the classification procedure (see

\footnotetext{
${ }^{3}$ Initially, "mortality and health" was broken down into two separate categories. We subsequently chose to combine the two categories because of sample size issues.
} 
Nieberg et al. 2014). Among the advantages of focusing on publications in Demography are that the papers tend to have a similar structure, and that most are quantitative studies with a clearly defined outcome variable. For example, an article on the effect of migration on first births would have been assigned to the subfield "fertility," while a study on the effect of fertility on migration decisions would have been assigned to the subfield "migration." Meanwhile, a paper that explored more than one outcome - for example, fertility and mortality processes - would have been assigned to the "other" category. Some papers focused not on a cause-effect relationship between variables, but on methodological aspects, such as improved measurement or data issues. Regardless of their content, we assigned these studies to the "methods and data" category.

This classification system is clearly subjective, and assignments may vary depending on the individual rater. However, to assess the reliability of the classification procedure, we instructed three independent raters to categorize a sample of the papers based on our classification rules. ${ }^{4}$ The three raters independently categorized the same sample of around 200 abstracts. Based on the categorization of this sample, we calculated the coefficient kappa, which measures the degree of agreement of different raters (Cohen 1960). The referring value of kappa was found to be above 0.80 , which indicates an acceptable level of agreement on the classification of the publications among these three raters.

\section{Methods}

We first describe the development of female authorship and the publications by research subfield over time. In a second step, we estimate a multinomial logit model in which the dependent variable is the demographic subfield in which an author is publishing. To adjust for multiple observations of articles, we use robust standard errors. The main independent variables are the gender of the author and the period of publication. Because our sample is small we decided to categorize the articles by decade, although the earliest group also includes the adjacent years (1964-1979, 1980-1989, 1990-1999, 2000-2009, 2010-2014). In addition, we control for the gender of the editor over time, based on the assumption that the gender of the editor who is involved in the review process might be related to the acceptance rates of papers in more female-dominated subfields (see Table 3 in the appendix for information on the gender of the editor over time, and Table 4 in the appendix for the descriptive statistics of our sample). To investigate how the role of gender in demographic subfields evolved over time, we include an interaction of calendar year and gender in the model.

\section{Descriptive Results}

Figure 1 displays the development over time of the share of the authors of publications in Demography who were women. From the first (1964-1979) to the most recent

\footnotetext{
${ }^{4}$ In order to classify the papers, the raters used the titles and the abstract. The authors' gender was not known to the raters.
} 


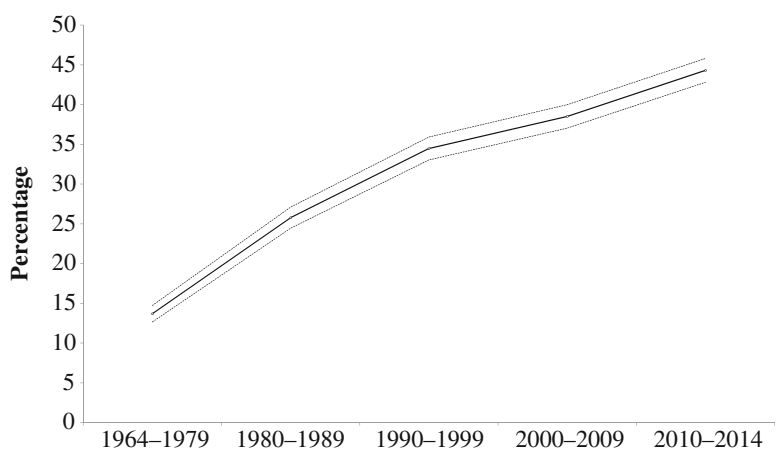

Fig. 1 Share of female authors in Demography over time and $95 \%$ confidence level. Unit of analysis is the authorship rather than the individual publication

period (2010-2014), this share rose from $14 \%$ to $44 \%$. These results are in line with the findings of West et al. (2013), who reported that demography is now among the most gender-equal fields of research with respect to publication output. Separate analyses of the shares of female authors among all authors who presented their research at the PAA annual meetings from 2002 to 2014 lend support to the argument that demography has become a gender-equal field of research, at least in terms of conference presentations. ${ }^{5}$ Unfortunately, we have no access to information on the gender breakdown of the scientists who submitted manuscripts to Demography. We do, however, know that the share of the students earning doctoral degrees in demography at U.S. institutions who are women has been increasing in recent decades and has been above $50 \%$ since 2000 (National Science Foundation 2015). Female authorship in Demography lags behind this trend. Because we do not know how many female and male $\mathrm{PhD}$ recipients go on to pursue an academic career and how many authors graduated from programs in other fields, these numbers are only suggestive and do not allow us to draw firm conclusions.

Figure 2 displays authorship status by calendar year and gender. We distinguish between sole authorship, first authorship, and coauthorship. The figure shows that publication practices have changed considerably over the years. Sole authorship was very common in Demography in 1964-1979: during that period, about half of all authors were sole authors. Since then, the prevalence of sole authorship has declined rapidly. In the period 2010-2014, for example, only $13 \%$ of all female authors were sole authors. At the same time, the share of those being a first author in a multipleauthored paper rose slightly. Interestingly, women and men were equally likely to have published a paper as the sole or first author. ${ }^{6}$

When considering the results of the analyses of research subfields over time, it is important to keep in mind that our focus is on the outcome variable. Taking this narrow view, we see some striking trends in Fig. 3, which maps the evolution of subfields. First, the relative significance of papers assigned to the "data and methods" category

\footnotetext{
${ }^{5}$ It would be interesting to compare this development with the total share of demographers who are women or with the percentage of members of the PAA who are female. Unfortunately, we do not have reliable time series information of this kind.

${ }^{6}$ We also did not find any evidence that male authors were more likely than female authors to have been the last author of a paper with multiple authors (results not shown here).
} 

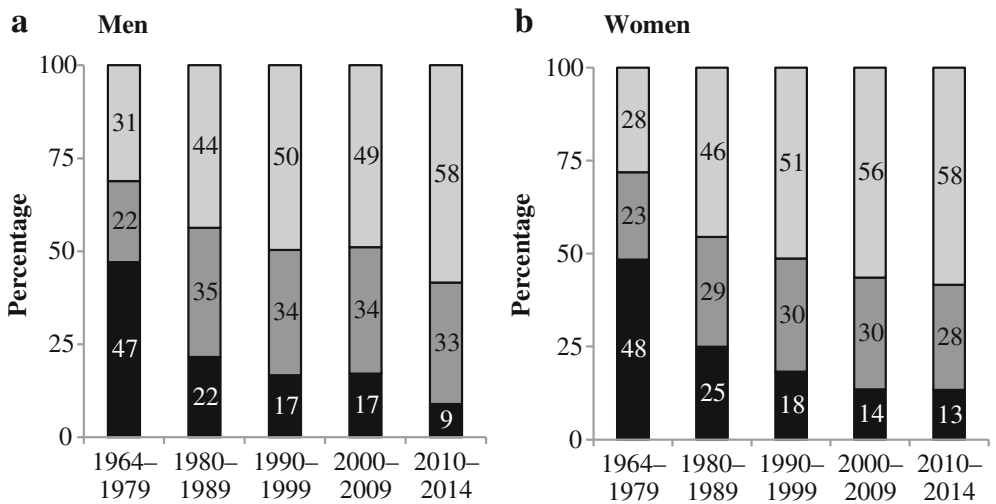

\section{$\square$ Coauthor $\square$ First author $\square$ Sole author}

Fig. 2 Authorship status by gender in Demography. Unit of analysis is the authorship rather than the individual publication

has declined over time: as a percentage of all of the papers published, the share of the papers that were in the subfield of "data and methods" fell from 19\% in 1964-1979 to $7 \%$ in 2010-2014. However, we cannot rule out the possibility that the decline in the number of papers in this category is an artifact attributable to the increased tendency to integrate methodological considerations into papers that also have a substantive topic. Looking at the number of articles that used an outcome variable related to one of the traditional demographic subfields of "fertility," "mortality and health," and "migration" reveals that the number of publications in the subfield of "mortality and health" has grown especially rapidly in recent decades. By contrast, despite the obvious social policy relevance of migration, the number of publications on this topic has remained

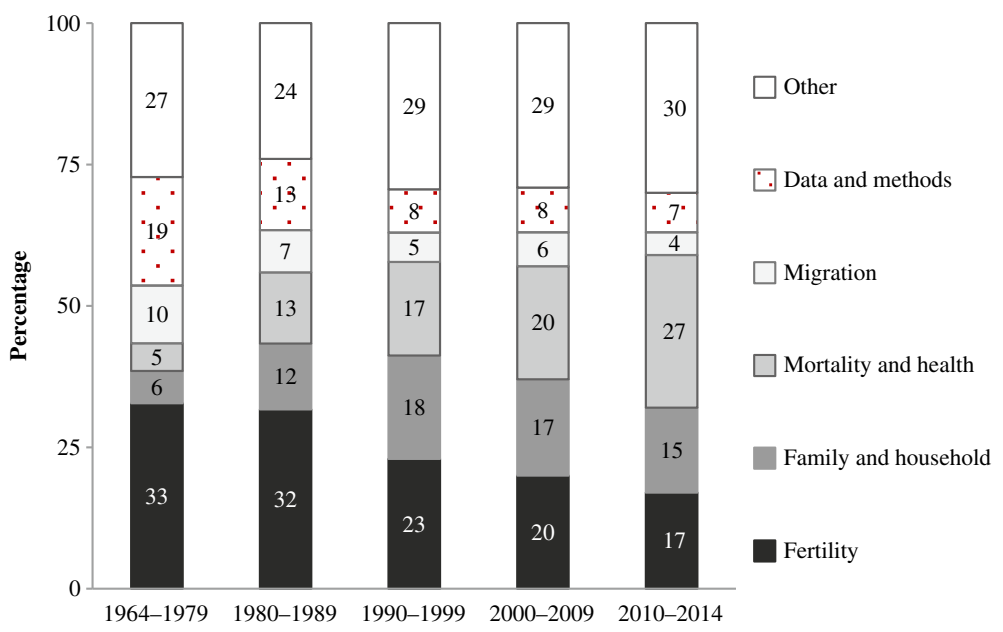

Fig. 3 Evolution of subfields of publication in Demography over time. Unit of analysis here is the individual publication 
small (see also Kirk 1968; Rößger 2014). The dearth of publications on migration may be attributable to a lack of data available to researchers in this subfield. However, we assigned some of the articles that dealt with the social aspects of migration — such as discrimination against migrants or the integration of them - to the "other" category in our investigation. This reveals the main shortcoming of our classification procedure, which assumes that each paper included a well-defined outcome variable. It is interesting to observe that articles with a fertility-related outcome variable have become less prevalent in Demography. Whereas the share of papers with a focus on "fertility" has declined, the share of papers analyzing an outcome variable in the area of "family and household" research has expanded in recent years, accounting for $15 \%$ of all publications in Demography in 2010-2014.

\section{Multivariate Results}

Table 1 displays the results of the multinomial logistic regression model with the subfield of study as the dependent variable. We chose "other" as the base category, given that descriptive statistics show that the gender composition in this subfield is almost constant over time. Our period indicator shows a pattern that is in line with the previous descriptive statistics. Over time, the relevance of articles in the categories "data and methods," "migration," and "fertility" declined; the relevance of papers in the categories "mortality and health" and "family and household" increased.

Our key variable of interest is gender. We find that women were less likely than men to have published papers in the categories "data and methods," "migration," and "mortality and health." We find no difference by gender in publications on fertility research. Women were substantially more likely than men to have published papers with outcome variables in "family and household" (the relative risk ratio was $61 \%$ higher for women than for men). To help determine whether this pattern has changed over time, Fig. 4 in the appendix displays the results from an interaction of gender and period. ${ }^{7}$ The figure shows a significant overrepresentation of women authors in the category "family and household" beginning in the 1980s. Since then, women have had higher relative risk ratios of publishing studies with a family- or household-related outcome variable.

The model also controls for the gender composition of the editors. We expected to find that female editors would be more supportive of publications in categories in which there are more female authors. However, we do not find strong evidence to support this assumption. Although female editorship was associated with an increase in the chances that a paper would be published in the category "family and household," the coefficient was significant at only the $5 \%$ level. In addition, female or mixed editorship increased the chances that a paper with a migration-related outcome variable would be published. However, the authorship of papers in this category was not dominated by women.

\footnotetext{
${ }^{7}$ The predicted probabilities for the interaction effect can be found in Table 5 in the appendix.
} 


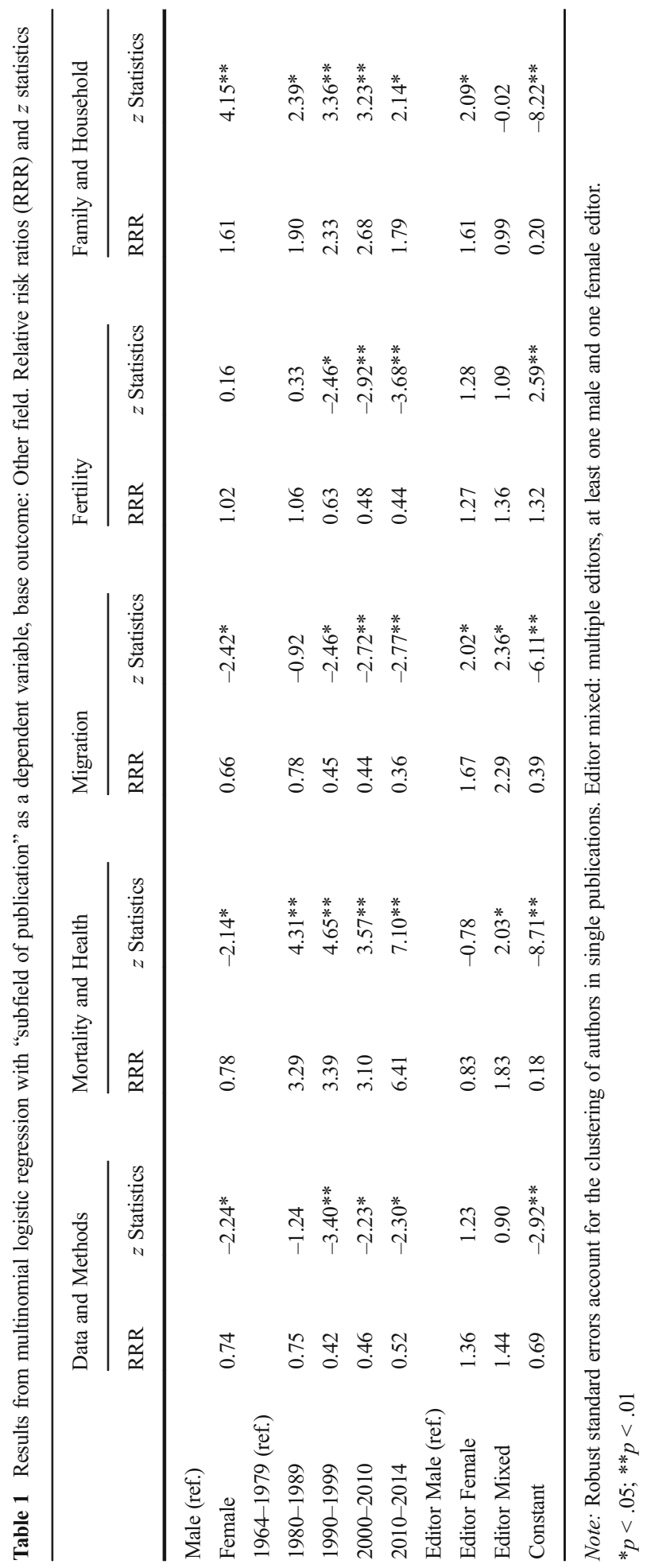




\section{Discussion}

In this study, we investigated the development of demographic research subfields and gendered publication practices by examining publications in Demography spanning the 50-year period of 1964-2014. More than $40 \%$ of all of the authors who published in Demography in the period 2010-2014 were female. This result corroborates previous findings that demography is more gender-balanced than most other fields of research. Moreover, we did not find that women have been disadvantaged in terms of coauthorship practices. Over the period studied, women were as likely as men to have been the sole author of a paper or the first author of a paper with multiple authors. Based on these simple descriptive statistics, it is tempting to conclude that Demography is a gender-equal journal.

However, some caution is warranted. Our findings indicate that although women are authoring more papers than in the past, they have not yet reached parity with men. The trend toward female authorship in demographic research has so far been positive, but we should carefully observe how this trend develops in the future. Other studies have, for example, shown that in several fields, the share of $\mathrm{PhD}$ recipients who are women has plateaued at levels below $50 \%$ (England 2010:160). A closer inspection of the subfields of publications in Demography also reveals gender differences by outcome variables. Our multivariate analyses indicate that women authors have been overrepresented in the "family and household" category, but they have been less likely to publish in the "mortality and health," "migration," and "data and methods" categories. Our scheme for categorizing research subfields is limited in a number of ways, including by the narrow identification based on the outcome variable and the large fraction of unclassifiable papers. We believe, however, that our findings provide evidence of some segregation by gender in the publications in Demography.

These results raise several questions. For example, are our findings representative of demography as a field of research, and do they reflect publication patterns in other journals, such as Population and Development Review and Population Studies? Furthermore, are the gendered publication patterns in Demography an indication of the exclusion of women (and men) from specific research subfields, or do they instead reflect different research interests among female researchers? We have shown in this article that gendered publication practices exist, but we have been unable to identify the mechanisms that produced these patterns. Our data also do not allow us to address the issue of whether gendered publication practices affect the academic advancement of women in demographic research. Moreover, examining the number of female submissions might have enabled us to assess whether female authors were subject to discrimination in the review process, but this information was not available. Although we were unable to answer these substantive questions, we hope that this descriptive paper motivates others to conduct more fine-grained analyses of gendered publication activities in demographic research.

Acknowledgments Open access funding is provided by Max Planck Society. A draft of this article was presented at the annual meeting of the Population Association of America in 2015. We are grateful for helpful comments from colleagues at the Max Planck Institute for Demographic Research, the Hertie School of Governance, and Stockholm University. We also thank Mark Fiegener of the National Science Foundation and the National Center for Science and Engineering Statistics for providing us with data from the Survey of Earned Doctorates. We thank Lois M. Brown of the PAA for providing us with data on the shares of PAA members by gender. For language editing, we thank Miriam Hils. Any remaining errors are entirely our own. Last but not least, we express our thanks to Valeria Nieberg for supporting us in compiling the data. 


\section{Appendix}

Table 2 List of keywords for classification scheme

\begin{tabular}{ll}
\hline Subfield & Keyword \\
\hline Fertility & $\begin{array}{l}\text { Births, birth rate, childbearing, childbearing desires/preferences, pregnancy spacing } \\
\text { of births, birth interval, reproductive health, sexual health/HIV, family planning } \\
\text { (programs), contraception, sterility, abortion, infanticide, sex ratio, fecundity, } \\
\text { miscarriage, fetal loss, abortion, breast-feeding, postpartum, amenorrhea }\end{array}$ \\
Family, partnerships, marriage, household, leaving home, institutional child \\
care/parental leave, elderly care, (gendered) division of labor, child support, child \\
well-being, intermarriage, kinship, homogamy \\
Mortality, survival, causes of death, infant/neonatal mortality, life expectancy, health, \\
aging, disability, transition to disability/care, care need, healthy life expectancy, healthy \\
behavior/risk behavior, birth weight, BMI/obesity, height \\
Migration processes, residential mobility, internal/international migration \\
Methods, statistics, calculus, dispersion, Bayesian forecasting, modeling/models, \\
stable population/stationary population, measures/measurement, population \\
composition, population projections, population growth, reporting errors, survey \\
methodology, data collection procedures \\
Migration \\
$\begin{array}{l}\text { Education, language/cognitive abilities, developmental outcomes, labor market, } \\
\text { transition to retirement, pension policy, wealth/poverty, income, income mobility, } \\
\text { neighborhood, residential distribution, ethnic inequality, integration/segregation, } \\
\text { socioeconomic status, environment, urbanization, domestic violence, social } \\
\text { networks, crime, demography as a field of research, review articles, } \\
\text { replies/comments, unclassifiable }\end{array}$ \\
Other
\end{tabular}

Table 3 Gender of the editor of Demography

Note: $\mathrm{M}=$ male editor; $\mathrm{F}=$ female editor; $\mathrm{M} / \mathrm{F}=$ multiple editors, with at least one male and one female.

\begin{tabular}{ll}
\hline Year & Gender \\
\hline $1964-1965$ & $\mathrm{M}$ \\
1966 & $\mathrm{M}$ \\
$1967-1968$ & $\mathrm{M}$ \\
$1969-1971$ & $\mathrm{~F}$ \\
1972 & $\mathrm{M}$ \\
$1973-1975$ & $\mathrm{M}$ \\
$1976-1978$ & $\mathrm{M}$ \\
$1979-1980$ & $\mathrm{M}$ \\
$1981-1984$ & $\mathrm{M}$ \\
$1985-1987$ & $\mathrm{~F}$ \\
$1988-1990$ & $\mathrm{M}$ \\
$1991-1993$ & $\mathrm{M}$ \\
$1994-1995$ & $\mathrm{~F}$ \\
$1996-1998$ & $\mathrm{M}$ \\
$1999-2001$ & $\mathrm{M} / \mathrm{F}$ \\
$2002-2004$ & $\mathrm{M}$ \\
$2005-2007$ & $\mathrm{M} / \mathrm{F}$ \\
$2008-2010$ & $\mathrm{M}$ \\
$2011-2013$ & $\mathrm{M}$ \\
$2014-2016$ & $\mathrm{~F}$ \\
\hline
\end{tabular}


Table 4 Descriptive statistics

\begin{tabular}{|c|c|c|c|c|}
\hline & \multicolumn{2}{|c|}{ Authorships } & \multicolumn{2}{|c|}{ Publications } \\
\hline & $n$ & Proportion & $n$ & Proportion \\
\hline Male & 2,917 & .70 & 1,598 & .71 \\
\hline Female & 1,280 & .30 & 654 & .29 \\
\hline 1964-1979 & 1,008 & .24 & 720 & .32 \\
\hline 1980-1989 & 772 & .18 & 424 & .19 \\
\hline 1990-1999 & 818 & .20 & 403 & .18 \\
\hline $2000-2009$ & 818 & .20 & 380 & .17 \\
\hline $2010-2014$ & 781 & .19 & 325 & .14 \\
\hline Editor Male & 2,967 & .71 & 1,646 & .73 \\
\hline Editor Female & 691 & .16 & 361 & .16 \\
\hline Editor Mixed & 539 & .13 & 245 & .11 \\
\hline Fertility & 1,122 & .27 & 590 & .26 \\
\hline Family and Household & 553 & .13 & 280 & .12 \\
\hline Mortality and Health & 656 & .16 & 316 & .14 \\
\hline Migration & 285 & .07 & 161 & .07 \\
\hline Data and Methods & 485 & .11 & 281 & .13 \\
\hline Other & 1,096 & .26 & 624 & .28 \\
\hline Number of Authorships & 4,197 & 1.00 & - & - \\
\hline Number of Publications & - & - & 2,252 & 1.00 \\
\hline
\end{tabular}

Note : Editor mixed = multiple editors, with at least one male and one female editor. 


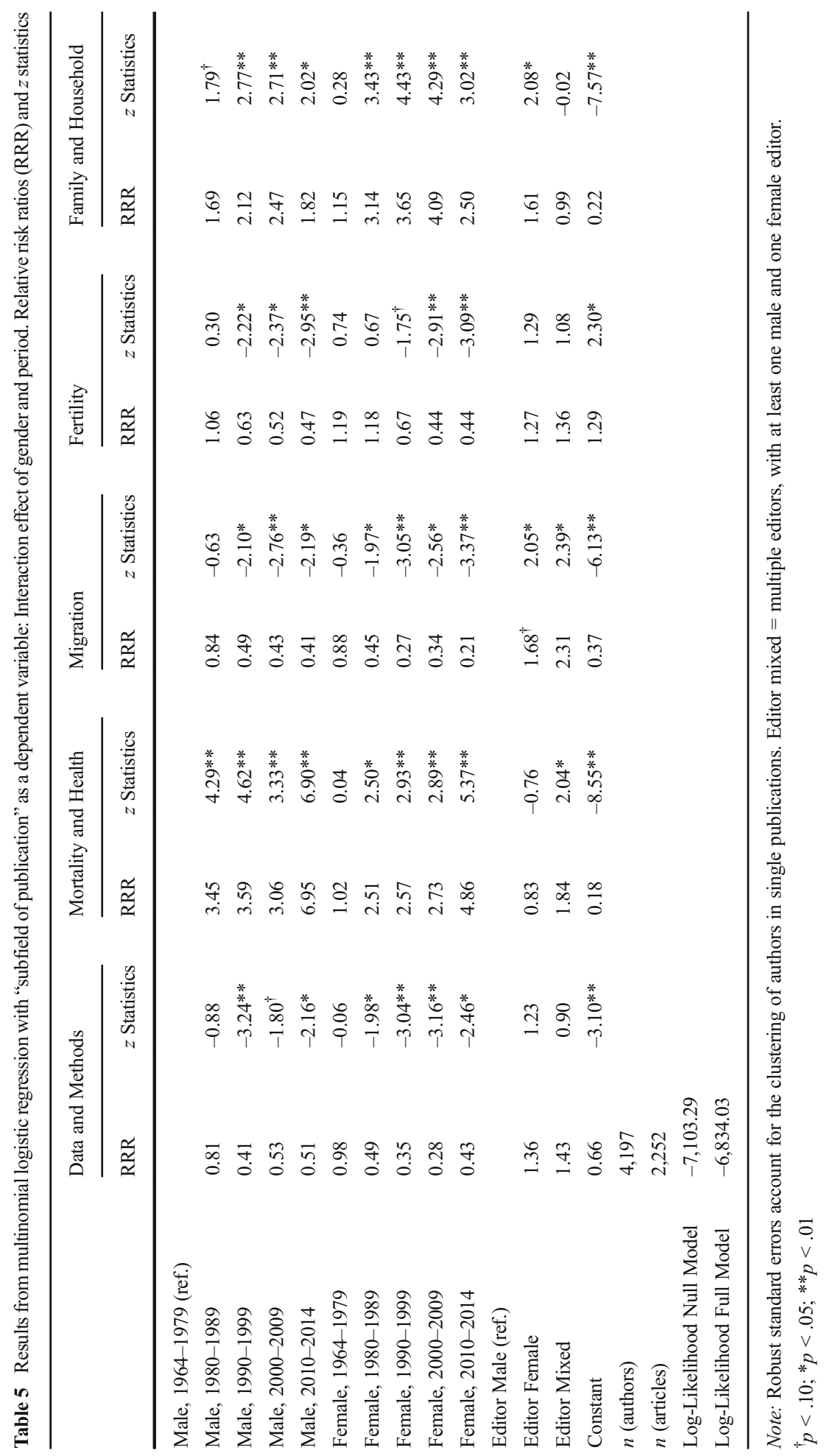



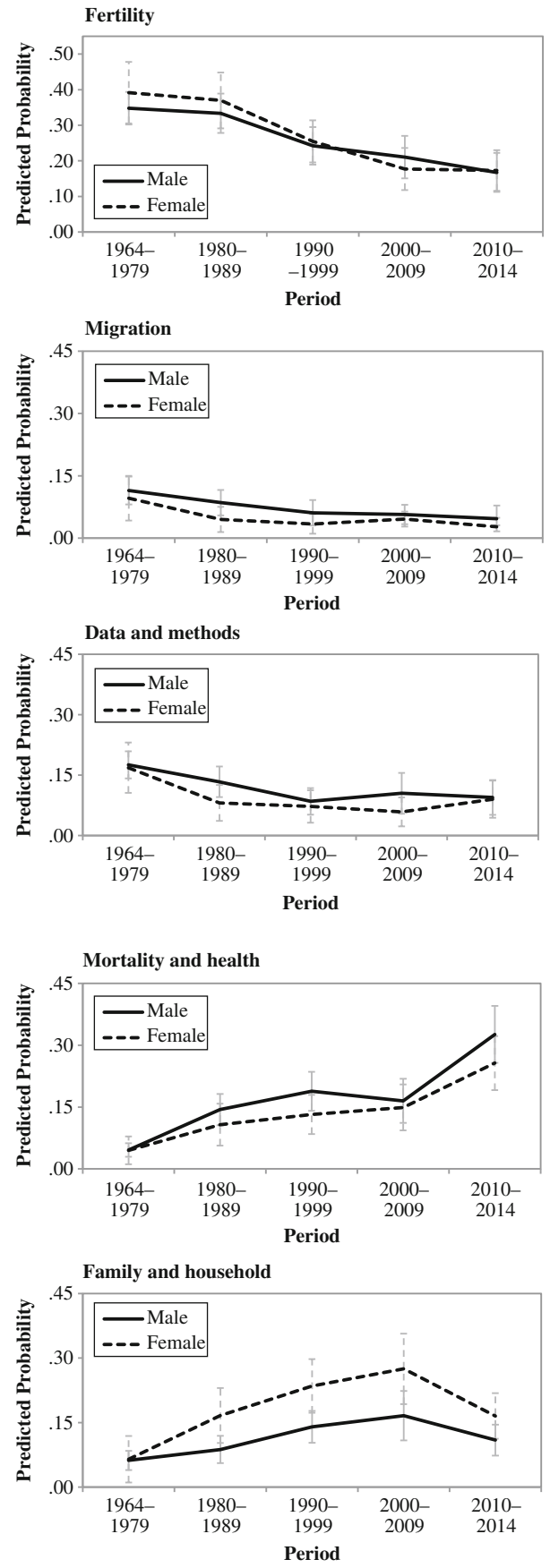

Fig. 4 Results of multinomial logit model. Predicted probabilities of publication for men and women by period and subfield and $95 \%$ confidence bounds. Robust standard errors are included to account for the clustering of authors in single publications. Detailed regression results will be provided upon request 
Open Access This article is distributed under the terms of the Creative Commons Attribution 4.0 International License (http://creativecommons.org/licenses/by/4.0/), which permits unrestricted use, distribution, and reproduction in any medium, provided you give appropriate credit to the original author(s) and the source, provide a link to the Creative Commons license, and indicate if changes were made.

\section{References}

Abramo, G., D’Angelo, C. A., \& Caprasecca, A. (2009). Gender differences in research productivity: A bibliometric analysis of the Italian academic system. Scientometrics, 79, 517-539.

Blau, F., Brummund, P., \& Liu, A.-H. (2013). Trends in occupational segregation by gender 1970-2009: Adjusting for the impact of changes in the occupational coding system. Demography, 50, 471-492.

Cohen, J. (1960). A coefficient of agreement for nominal scales. Educational and Psychological Measurement, 20, 37-46.

Cohen, L. E., Broschak, J. P., \& Haveman, H. A. (1998). And then there were more? The effect of organizational sex composition on the hiring and promotion of managers. American Sociological Review, 63, 711-727.

Dehdarirad, T., Villarroya, A., \& Barrios, M. (2015). Research on women in science and higher education: A bibliometric analysis. Scientometrics, 103, 795-812.

Dolado, J. J., Felgueroso, F., \& Almunia, M. (2012). Are men and women-economists evenly distributed across research fields? Some new empirical evidence. SERIEs, 3, 367-393.

England, P. (2010). The gender revolution: Uneven and stalled. Gender and Society, 24, 149-166.

Gonzales, L. M., Allum, J. R., \& Sowell, R. S. (2013). Graduate enrollment and degrees: 2002 to 2012 (Survey report). Washington, DC: Council of Graduate Schools.

Kirk, D. (1968). The field of demography. International Encyclopedia of the Social Sciences, 12, 342-349.

Leahey, E. (2006). Gender differences in productivity: Research specialization as a missing link. Gender and Society, 20, 754-780.

Maliniak, D., Powers, R., \& Walter, B. F. (2013). The gender citation gap in international relations. International Organization, 67, 889-922.

Mauleon, E., Hillan, L., Moreno, L., Gómez, I., \& Bordons, M. (2013). Assessing gender balance among journal authors and editorial board members. Scientometrics, 95, 87-114.

Merchant, E. R. (2015). Prediction and control: Global population, population science, and population politics in the twentieth century (Unpublished doctoral dissertation). University of Michigan, Ann Arbor, MI.

National Science Foundation. (2015). Survey of earned doctorates (Special tabulation, May 2015). Arlington, VA: National Center for Science and Engineering Statistics, NSF/NIH/ED/USDA/ $\mathrm{NEH} / \mathrm{NASA}$.

Nieberg, V., Krapf, S., Kreyenfeld, M., \& Wolf, K. (2014). Construction of a publication database of the scientific journal "Demography": How to identify author's gender and field of publication (MPIDR Technical Report No. 2014-02). Rostock, Germany: Max Planck Institute for Demographic Research. Retrieved from http://www.demogr.mpg.de/papers/technicalreports/tr-2014-002.pdf

OECD. (2012). Closing the gender gap: Act now. Paris, France: OECD Publishing. Retrieved from http:// dx.doi.org/10.1787/9789264179370-en

Østby, G., Strand, H., Gleditsch, N. P., \& Nordås, R. (2013). Gender gap or gender bias in peace research? Publication patterns for Journal of Peace Research, 1983-2008. International Studies Perspectives, 14, 493-506.

Ramsden, P. (1994). Describing and explaining research productivity. Higher Education, 28, 207-226.

Reskin, B. (1993). Sex segregation in the workplace. Annual Review of Sociology, 19, 241-270.

Rößger, F. (2014). Demographic perspectives on international migration (Unpublished doctoral dissertation). Universität Rostock, Rostock, Germany.

Teachman, J. D., Paasch, K., \& Carver, K. P. (1993). Thirty years of Demography. Demography, 30, 523-532.

Tower, G., Plummer, J., \& Ridgewell, B. (2007). A multidisciplinary study of gender-based research productivity in the world's best journals. Journal of Diversity Management, 2(4), 23-32.

Trappe, H., \& Rosenfeld, R. A. (2004). Occupational sex segregation and family formation in the former East and West Germany. Work and Occupations, 31, 155-192.

Watkins, S. C. (1993). If all we knew about women was what we read in Demography, what would we know? Demography, 30, 551-577. 
West, J. D., Jacquet, J., King, M. M., Correll, S. J., \& Bergstrom, C. T. (2013). The role of gender in scholarly authorship. PLoS ONE, 8(7), e66212. doi:10.1371/journal.pone.0066212

Woerdeman, D. L., \& Van der Meulen Rodgers, Y. (2006). Work styles, attitudes, and productivity of scientists in the Netherlands and the United Kingdom: A comparison by gender. Management Revue, 17, 184-202. 